\title{
The Stimulus-Secretion Coupling of 4-Methyl-2-oxopentanoate-Induced Insulin Release
}

\author{
By John C. HUTTON,* Abdullah SENER and Willy J. MALAISSE \\ Laboratory of Experimental Medicine, University of Brussels, Brussels, Belgium
}

(Received 4 May 1979)

\begin{abstract}
1. Pancreatic islet insulin secretion and ${ }^{45} \mathrm{Ca}$ uptake showed similar responses to variation in the extracellular concentration of 4-methyl-2-oxopentanoate with a threshold at $4 \mathrm{~mm}$ and a maximal response at a $25 \mathrm{~mm}$ concentration. 2 . Islet respiration, acetoacetate production and rates of substrate utilization, oxidation and amination all changed as a simple hyperbolic function of 4-methyl-2-oxopentanoate concentration and exhibited a maximal response at $25 \mathrm{~mm}$. 3. The responses of ATP content, [ATP]/[ADP] ratio, adenylate energy charge and $[\mathrm{NADH}] /\left[\mathrm{NAD}^{+}\right]$ratio were also hyperbolic in nature but were maximally elevated at lower concentrations of the secretagogue. The islet [NADPH]/ $\left[\mathrm{NADP}^{+}\right.$] ratio, however, was tightly correlated with parameters of metabolic flux, ${ }^{45} \mathrm{Ca}$ uptake and insulin release. $4 . \mathrm{NH}_{4}{ }^{+}$and menadione, agents that promote a more oxidized state in islet NADP, did not affect islet ATP content or the rates of $\left[\mathrm{U}-{ }^{14} \mathrm{C}\right] 4-$ methyl-2oxopentanoate oxidation or amination, but markedly inhibited islet ${ }^{45} \mathrm{Ca}$ uptake and insulin release. 5. It is proposed that changes in the redox state of NADP and Ca transport may serve as mediators in the stimulus-secretion coupling mechanism of insulin release induced by 4-methyl-2-oxopentanoate.
\end{abstract}

In the preceding paper (Hutton et al., 1979c) the intermediary metabolism of 4-methyl-2-oxopentanoate in rat pancreatic islets was investigated. The present report considers the inter-relationship between changes induced by 4-methyl-2-oxopentanoate in islet metabolic fluxes and the intracellular content of adenine and nicotinamide nucleotides. The significance of such metabolic phenomena to the regulation of islet-cell function, as reflected in changes in cation transport and insulin release, was examined. The dependence of each of these parameters on the extracellular concentration of 4-methyl-2-oxopentanoate was investigated, together with the effect on islet-cell metabolism and function of agents that perturb the redox state of islet nicotinamide nucleotides.

\section{Experimental}

Isolated islets obtained from fed female rats (Wistar strain; about $200 \mathrm{~g}$ body wt.) by the technique of Lacy \& Kostianovsky (1967) were incubated in a bicarbonate-buffered medium (Malaisse et al.,

* Present address: Department of Clinical Biochemistry, Addenbrooke's Hospital, Hills Road, Cambridge CB2 2QR, U.K.
1970) containing bovine serum albumin $(5 \mathrm{mg} / \mathrm{ml}$; Sigma, St. Louis, MO, U.S.A.) and equilibrated with $\mathrm{O}_{2} / \mathrm{CO}_{2}$ (19:1).

\section{Insulin release, ${ }^{45} \mathrm{Ca}$ uptake and metabolic fluxes}

The methods used for the measurement of insulin release (Malaisse et al., 1970), ${ }^{45} \mathrm{Ca}$ uptake (MalaisseLagae \& Malaisse, 1971) and metabolic fluxes (Hutton et al., 1979c) in the islets have been previously reported.

Determination of islet content of adenine and nicotinamide nucleotides

Islet contents of $\mathrm{NAD}^{+}, \mathrm{NADH}$, total NAD, NADP $^{+}$, NADPH and total NADP were determined by enzymic cycling techniques (Lowry \& Passonneau, 1972). ATP, ADP and AMP were determined in enzyme reactions coupled to the firefly luciferase reaction (Stanley \& Williams, 1969). Groups of seven or 10 islets, placed in polythene microcentrifuge tubes (Beckman, Fullerton, CA, U.S.A.), were preincubated in $50 \mu$ l of incubation medium, $\mathrm{pH} 7.5$, for $30 \mathrm{~min}$ at $37^{\circ} \mathrm{C}$ in the absence of added substrate, and then exposed for $15 \mathrm{~min}$ at $37^{\circ} \mathrm{C}$ to $50 \mu \mathrm{l}$ of medium containing 4-methyl-2-oxopentanoate 
(1-50 mM). Most of the incubation medium was then withdrawn (at $37^{\circ} \mathrm{C}$ ), and the tubes were placed in a Freon 12 bath that was cooled in liquid $\mathbf{N}_{2}$. Subsequent steps in the preparation and analysis have been described previously (Malaisse et al., 1978a). All reagents used in these assays were obtained from either Boehringer, Mannheim, West Germany or Sigma. Enzymes and ADP were treated as described by Lowry \& Passonneau (1972) to remove contaminating nucleotides. Strict attention was given to the quantity of lactate dehydrogenase (EC 1.1.1.27) used in the NAD analyses, since this enzyme also catalyses the reduction of 4-methyl-2-oxopentanoate, albeit at a low rate.

\section{Presentation of results}

Results are expressed throughout as means \pm S.E.M., the number of independent observations being shown in parentheses. Probability estimates were made by using Student's $t$ test.

\section{Results}

Concentration-dependence of parameters of metabolic flux

The effect of variation of the extracellular 4methyl-2-oxopentanoate concentration on the metabolic fate of this substrate in islet tissue and on isletcell respiration is shown in Fig. 1 . In each case the response was in the form of a rectangular hyperbola with its origin at zero concentration, a half-maximal response at 3-6 $\mathrm{mm}$ and a maximal response between $25 \mathrm{~mm}$ - and 50 mM-4-methyl-2-oxopentanoate. At all concentrations tested the rate of 4-methyl-2-oxo$\left[1-{ }^{14} \mathrm{C}\right]$ pentanoate decarboxylation was equivalent to the rate of ${ }^{3} \mathrm{H}_{2} \mathrm{O}$ production from 4-methyl-2-oxo$\left[4,5-{ }^{3} \mathrm{H}\right]$ pentanoate and was identical with the rate of catabolism that could be predicted from the rates of $\left[\mathrm{U}-{ }^{14} \mathrm{C}\right] 4-$ methyl-2-oxopentanoate oxidation and acetoacetate production. The rate of amination of $\left[\mathrm{U}-{ }^{14} \mathrm{C}\right] 4-m e t h y l-2$-oxopentanoate increased in a manner parallel to the rate of oxidation of the $\mathrm{U}-{ }^{14} \mathrm{C}$-labelled substrate. The ratio of these parameters when determined at different substrate concentrations in the same experiment did not vary significantly. The rate of islet respiration increased in a manner parallel to the rate of $\left[\mathrm{U}-{ }^{14} \mathrm{C}\right] 4-$ methyl-2-oxopentanoate oxidation, with an apparent ${ }^{14} \mathrm{CO}_{2} / \mathrm{O}_{2}$ stoicheiometry of about 0.8 at all concentrations of 4-methyl-2-oxopentanoate.

Effect of 4-methyl-2-oxopentanoate on islet content of nicotinamide nucleotides

The islet NADH content was increased on the addition of 4-methyl-2-oxopentanoate to the in- cubation medium, and this was accompanied by a complementary fall in islet $\mathrm{NAD}^{+}$content (Fig. 2). These changes, when expressed as the [NADH]/ $\left[\mathrm{NAD}^{+}\right]$ratio, appeared to be a continuous function of the extracellular 4-methyl-2-oxopentanoate concentration in the $1-10 \mathrm{~mm}$ range. The total islet content of NAD (oxidized and reduced forms), determined directly on an ice-cold alkaline homogenate of islet tissue, was equivalent to the summation of $\mathrm{NAD}^{+}$and NADH contents determined individually. Total NAD was unaffected by 4-methyl2-oxopentanoate, except at the highest concentration of the substrate. The half-maximal response in the islet [NADH]/[NAD $\left.{ }^{+}\right]$ratio occurred at $2.5 \mathrm{~mm}-4-$ methyl-2-oxopentanoate, a value that is lower than those observed for parameters of metabolic flux (Fig. 1). Also unlike these parameters, the [NADH]/ $\left[\mathrm{NAD}^{+}\right]$ratio attained a maximal value in response to 4-methyl-2-oxopentanoate at a $10 \mathrm{~mm}$ concentration and tended to decline at higher substrate concentrations. A more reduced state of NADP was observed in islets exposed to 4-methyl-2-oxopentanoate. The changes in islet NADPH and NADP ${ }^{+}$ contents were complementary, and the total NADP content was not affected. The islet [NADPH]/ $\left[\mathrm{NADP}^{+}\right.$] ratio increased in a hyperbolic manner in response to increasing 4-methyl-2-oxopentanoate concentrations. The half-maximal response in this parameter was observed at $7 \mathrm{~mm}$ and the maximal response at $25 \mathrm{~mm}-4$-methyl-2-oxopentanoate, both values being higher than the corresponding values observed in the concentration-dependence relationship of the islet $[\mathrm{NADH}] /\left[\mathrm{NAD}^{+}\right]$ratio. Investigation of the time course of the changes in islet content of nicotinamide nucleotides revealed that $30 \mathrm{~s}$ after the introduction of 4-methyl-2-oxopentanoate (10mM) the changes in the [NADH]/[NAD ${ }^{+}$] and [NADPH]/ [NAD ${ }^{+}$] ratios were 64.2 and $66.0 \%$ respectively of the values observed after a $5 \mathrm{~min}$ exposure to the substrate.

\section{Effect of 4-methyl-2-oxopentanoate on islet content of adenine nucleotides}

The ATP content of islet tissue was increased after the addition of 4-methyl-2-oxopentanoate to the incubation media, the increase being mainly attributable to an increase in the relative contribution of ATP to the total adenylate pool. The sum content of islet ATP, ADP and AMP tended to be greater in islets incubated in the presence of 4-methyl-2oxopentanoate than in islets incubated without exogenous substrate. The relationship of islet ADP and AMP content to the islet ATP content were consistent with the equilibration of the three nucleotides in the reaction catalysed by adenylate kinase (EC 2.7.4.3). The mass-action ratio for this reaction $\left([\mathrm{ATP}] \times[\mathrm{AMP}] /[\mathrm{ADP}]^{2}\right)$, determined in islets in- 

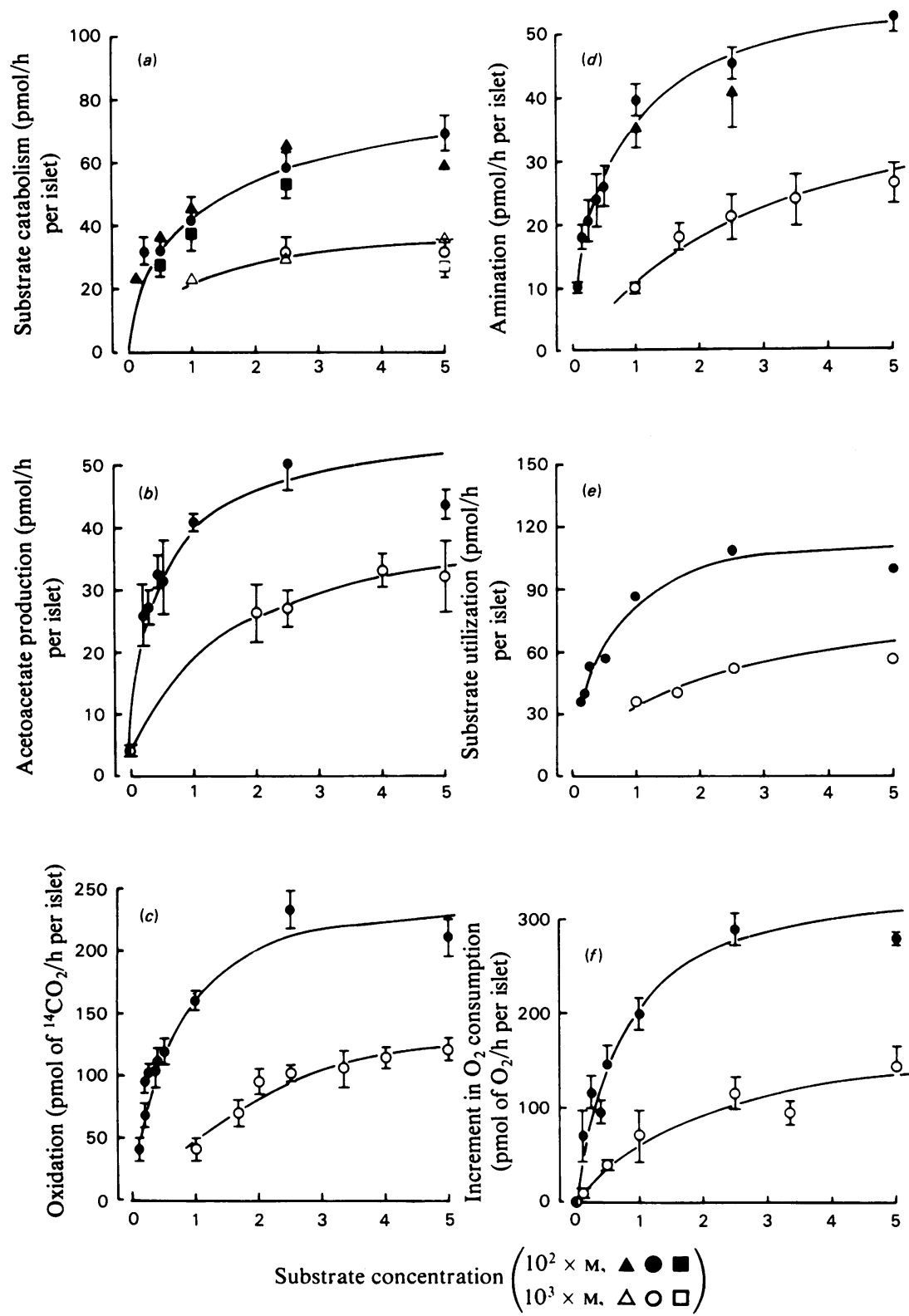

Fig. 1. Relationship of various metabolic parameters to the extracellular 4-methyl-2-oxopentanoate concentration in rat pancreatic islets

All determinations were performed over a $2 \mathrm{~h}$ incubation period with batches of 15 islets, except for respiratory determinations, which were steady-state measurements obtained in a perfusion system. The rates of 4-methyl-2-oxopentanoate catabolism in (a) expressed as pmol of substrate/h per islet were determined from the rates of ${ }^{14} \mathrm{CO}_{2}$ production from 4-methyl-2-oxo[1-14 $\mathrm{C}]$ pentanoate $(\mathrm{O}, \bullet)$, the rate of ${ }^{3} \mathrm{H}_{2} \mathrm{O}$ formation from 4-methyl-2-oxo[4,5- $\left.{ }^{3} \mathrm{H}\right]$ pentanoate $(\square, \square)$ or were calculated $(\triangle, \Lambda)$ from the sum of half the rate of acetoacetate production $(b)$ plus one-sixth of the rate of oxidation, as judged from the conversion of $\left[\mathrm{U}-{ }^{14} \mathrm{C}\right] 4-$ methyl-2-oxopentanoate into ${ }^{14} \mathrm{CO}_{2}(c)$. The rate of amination expressed as pmol of substrate aminated/h per islet is shown in $(d)$ for experiments performed with either the $U-{ }^{14} \mathrm{C}$ labelled $(O, \bullet)$ or the $1-{ }^{14} \mathrm{C}$-labelled $(\Delta)$ precursor. The sum of the rates of amination and catabolism is shown in $(e)$ expressed as pmol of substrate/h per islet. Each plotted value is the mean \pm S.E.M. of results obtained from 8-105 incubations. Two concentration scales are shown for 4-methyl-2-oxopentanoate, open symbols representing the $0-5 \mathrm{~mm}$ range and filled symbols the $0-50 \mathrm{~mm}$ range. 

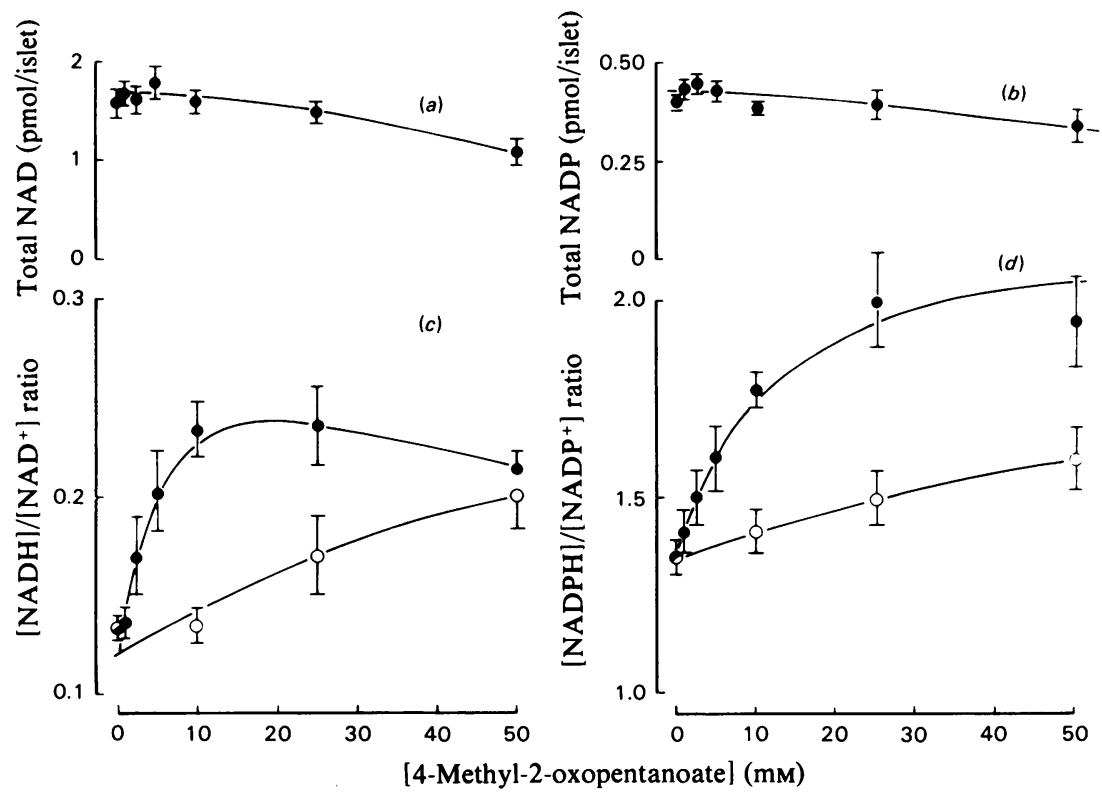

Fig. 2. Effect of variation of the extracellular concentration of 4-methyl-2-oxopentanoate on the contents of nicotinamide nucleotides of rat pancreatic islets

The whole islet contents of nicotinamide nucleotides were determined after a $15 \mathrm{~min}$ exposure at $37^{\circ} \mathrm{C}$ to the indicated extracellular concentrations of 4-methyl-2-oxopentanoate. The total NAD and NADP contents shown $(a, b)$ were obtained from direct determinations on an homogenate of islets in ice-cold alkaline media. The [NADH]/[NAD ${ }^{+}$] and [NADPH]/[NADP $\left.{ }^{+}\right]$ratios $(c, d)$ represent the observed proportion of the reduced and oxidized forms determined separately after treatment of the initial homogenate to destroy either the oxidized or reduced form of the nucleotide (Lowry \& Passonneau, 1972). Each plotted value is the mean \pm S.E.M. of results obtained in 17-103 separate incubations. Two substrate concentration scales are shown, representing the $0-5 \mathrm{~mm}$ (open symbols) or the 0-50 $\mathrm{mm}$ (filled symbols) range.

cubated in the absence of substrate, was $1.57 \pm 0.27$ $(n=80)$, a value that is similar to the reported $K_{\text {eq. }}$. of the adenylate kinase reaction in vivo (Alberty, 1969; Atkinson, 1977). The mass-action ratio was not significantly affected by 4-methyl-2-oxopentanoate at any of the concentrations tested. The ratio of islet $[\mathrm{ATP}] /[\mathrm{ADP}]$ and the adenylate energy charge ([ATP + $\left.\frac{1}{2} \mathrm{ADP}\right] /[\mathrm{ATP}+\mathrm{ADP}+\mathrm{AMP}]$ ) (Atkinson, 1966 ) both increased in response to 4-methyl-2-oxopentanoate in a manner that paralleled the effect of this substrate on islet ATP content (Fig. 3). The changes induced by 4-methyl-2-oxopentanoate in the islet adenylate nucleotides showed a concentrationdependence that differed strikingly from those of islet nicotinamide nucleotide contents (Fig. 2) or of parameters of metabolic flux (Fig. 1). At a concentration of $1 \mathrm{~mm}$, for example, 4-methyl-2-oxopentanoate induced a maximal change in islet ATP content and virtually no change in the ratios of islet [NADH]/ $\left[\mathrm{NAD}^{+}\right]$and [NADPH]/[NADP ${ }^{+}$. At such a concentration oxidation of $\left[\mathrm{U}-{ }^{14} \mathrm{C}\right] 4-$ methyl-2oxopentanoate was less than $20 \%$ of its maximal value.
Relationship of islet ${ }^{45} \mathrm{Ca}$ uptake to extracellular 4-methyl-2-oxopentanoate concentration

In contrast with the various metabolic parameters hitherto considered, islet net ${ }^{45} \mathrm{Ca}$ uptake was unaffected by 4-methyl-2-oxopentanoate at concentrations of less than $4 \mathrm{~mm}$ (Fig. 4). At higher concentrations, however, the oxo acid provoked an increase in islet net ${ }^{45} \mathrm{Ca}$ uptake that was maximally expressed at a concentration of the substrate of $25 \mathrm{~mm}$. Results that were qualitatively similar to those shown in Fig. 4 were also obtained by using a method for the determination of net ${ }^{45} \mathrm{Ca}$ uptake (Malaisse et al., 1978b) that does not rely on extensive washing of islet tissue after the initial incubation (J. C. Hutton \& W. J. Malaisse, unpublished work).

Relationship between insulin secretion and the 4methyl-2-oxopentanoate concentration of the medium

Insulin release was not significantly affected by 4-methyl-2-oxopentanoate in concentrations up to $4 \mathrm{~mm}$ (Fig. 5). Higher concentrations of the substrate, 

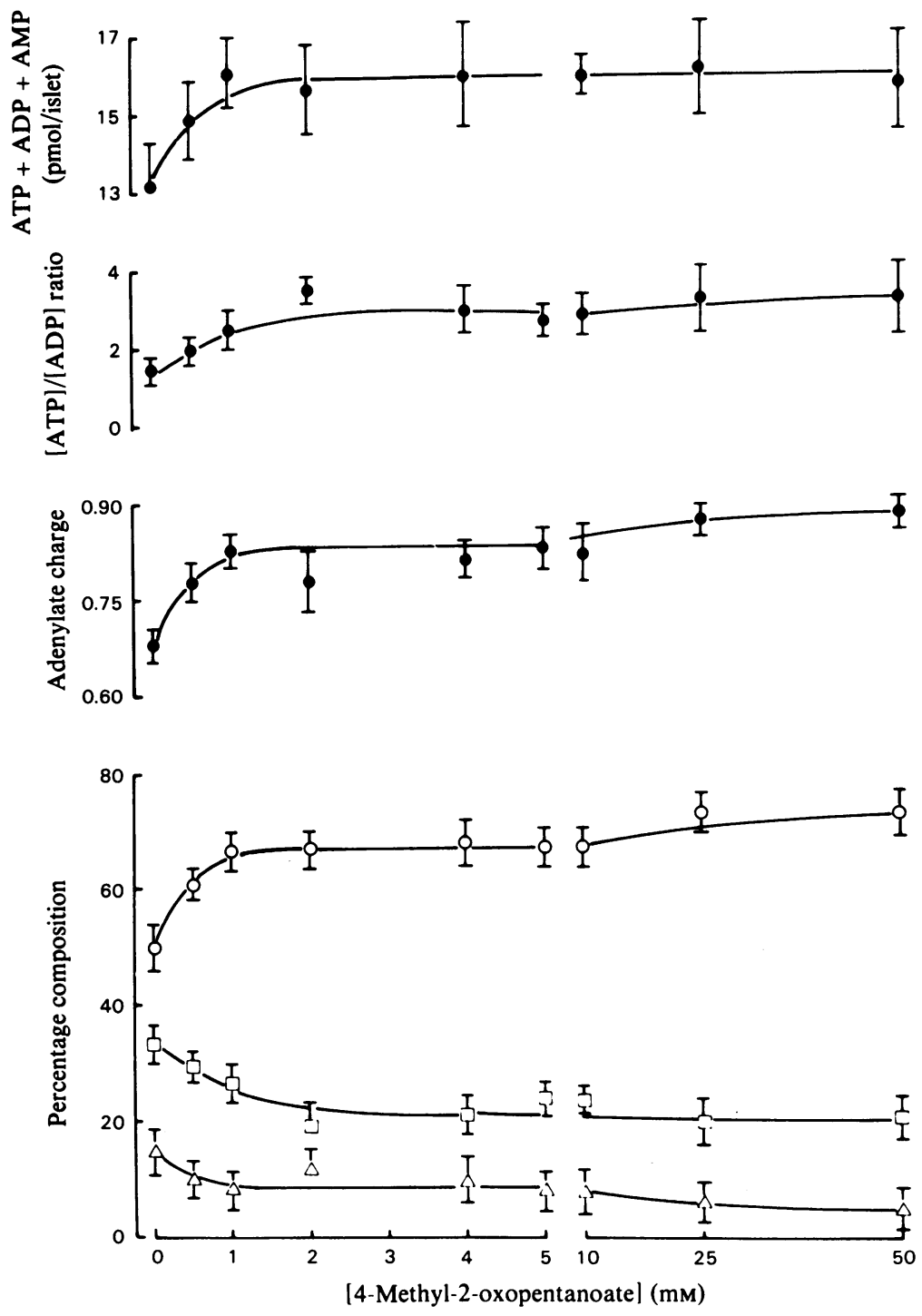

Fig. 3. Effect of variation in the extracellular 4-methyl-2-oxopentanoate concentration on islet contents of ATP, ADP and AMP The islet contents of ATP, ADP and AMP were determined after a 15 min exposure at $37^{\circ} \mathrm{C}$ to the indicated concentrations of 4-methyl-2-oxopentanoate. The relative contents of ATP $(O), \operatorname{ADP}(\square)$ and AMP $(\triangle)$ are shown, together with the adenylate energy charge ([ATP+ $\left.\frac{1}{2} A D P\right] /[A T P+A D P+A M P] ;$ Atkinson, 1966), the $[A T P] /[A D P]$ ratio and the content of ATP + ADP + AMP. Each plotted value is the mean \pm S.E.M. from analyses performed in 8-31 separate incubations.

however, provoked a marked increase in insulin secretion, a maximal response being observed in the presence of $25-50 \mathrm{~mm}-4$-methyl-2-oxopentanoate. The increase in insulin release induced by 4-methyl2-oxopentanoate was related linearly to the logarithm of the secretagogue concentration. The threshold of the insulinotropic response which could be extrapolated from such representations occurred at $3.8 \mathrm{~mm}$. Similar treatment of the results obtained for rat islet net ${ }^{45} \mathrm{Ca}$ uptake (Fig. 4) indicated that the threshold responses of this parameter occurred at 4.0 mM-4-methyl-2-oxopentanoate.

Vol. 184 


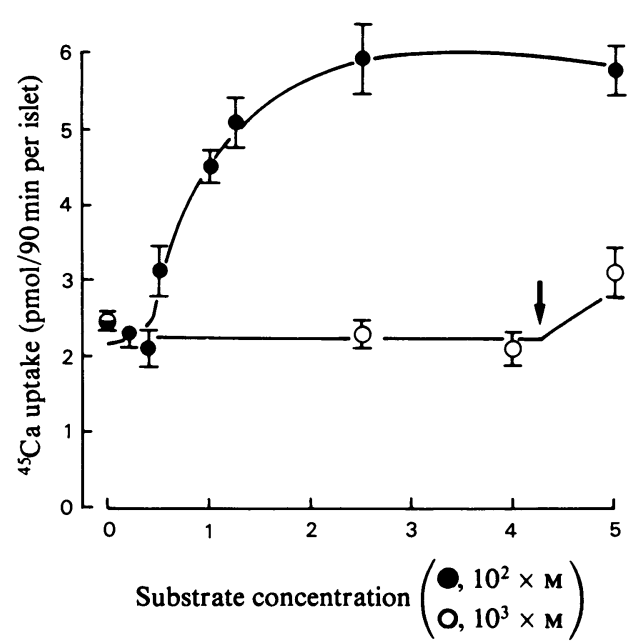

Fig. 4. Relationship of islet net ${ }^{45} \mathrm{Ca}$ uptake to the extracellular 4-methyl-2-oxopentanoate concentration

Islets were incubated for $90 \mathrm{~min}$ at $37^{\circ} \mathrm{C}$ in the presence of ${ }^{45} \mathrm{Ca}(1 \mathrm{mM}, 50 \mu \mathrm{Ci} / \mathrm{ml})$ and the indicated concentrations of 4-methyl-2-oxopentanoate. Extracellular and superficial pools of ${ }_{-5}^{45} \mathrm{Ca}$ were removed by rinsing the islets at $4^{\circ} \mathrm{C}$ in media devoid of radioisotope, and the radioactivity was then determined in groups of eight islets. Each plotted value is the mean \pm S.E.M. for 12-300 separate analyses. Two concentration scales are shown representing the $0-5 \mathrm{~mm}$ (open symbols) and a 0-50 mM (filled symbols) range. The arrow indicates the threshold concentration, which was determined from semilogarithmic plots of the data shown.

Effects of various modifiers of the nicotinamide nucleotide redox state on islet cell metabolism and function in the presence of 4-methyl-2-oxopentanoate

As shown in Table 1, the total NAD contents or total NADP contents of islets incubated in the presence of 4-methyl-2-oxopentanoate ( $10 \mathrm{~mm})$ were not affected by the addition of $\mathrm{NH}_{4} \mathrm{Cl}(5 \mathrm{mM})$ or menadione $(20 \mu \mathrm{M})$ to the incubation medium or by modification of the $p \mathrm{O}_{2}$ of the medium $\left(18-95 \% \mathrm{O}_{2}\right.$, $\mathrm{v} / \mathrm{v})$. The presence of $\mathrm{NH}_{4}{ }^{+}$in the incubation, however, caused a fall in both islet [NADH]/[NAD $\left.{ }^{+}\right]$ and [NADPH]/[NADP ${ }^{+}$] ratios, the values observed in the presence of 4-methyl-2-oxopentanoate $(10 \mathrm{~mm})$ being lower than those in islets incubated in the absence of exogenous substrate. The addition of menadione to the incubation had a more pronounced inhibitory effect than $\mathrm{NH}_{4}{ }^{+}$on the [NADPH]/ $\left[\mathrm{NADP}^{+}\right]$ratio, but it only slightly affected the $[\mathrm{NADH}] /\left[\mathrm{NAD}^{+}\right]$ratio observed in islets incubated in the presence of 4-methyl-2-oxopentanoate $(10 \mathrm{~mm})$. A decrease in the $\mathrm{O}_{2}$ concentration in the medium to about one-fifth of that normally used, in contrast

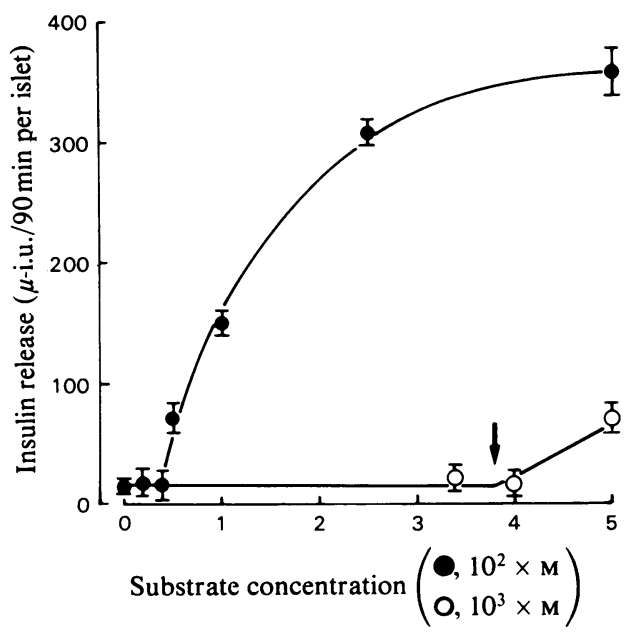

Fig. 5. Effect of variation of the extracellular 4-methyl-2oxopentanoate concentration on the release of insulin by rat pancreatic islets

Groups of eight islets were incubated for $90 \mathrm{~min}$ at $37^{\circ} \mathrm{C}$ in $1 \mathrm{ml}$ of Krebs-Henseleit buffer, $\mathrm{pH}$ 7.5. The content of insulin found in the medium at the end of the incubation period is shown in relationship to the extracellular 4-methyl-2-oxopentanoate concentration. Each plotted value is the mean \pm S.E.M. for results obtained in 12-300 separate incubations. Two concentration scales are shown representing the $0-5 \mathrm{~mm}$ (open symbols) and the $0-50 \mathrm{~mm}$ (filled symbols) range. The arrow $(\downarrow)$ indicates the threshold concentration, which was determined from semilogarithmic plots of the data shown.

with the effects of $\mathrm{NH}_{4}{ }^{+}$and menadione, caused a marked increase in the $[\mathrm{NADH}] /\left[\mathrm{NAD}^{+}\right]$ratio and a marginal increase in the [NADPH]/[NADP ${ }^{+}$] ratio in islets incubated with 4-methyl-2-oxopentanoate $(10 \mathrm{~mm})$. The ATP content of islets incubated in the presence of 4-methyl-2-oxopentanoate $(10 \mathrm{~mm})$ was not affected by the addition of $\mathrm{NH}_{4}{ }^{+}$or menadione to the incubation medium and was only slightly decreased when islets were incubated in the presence of a lower $p \mathrm{O}_{2}$. The rate of $\left[\mathrm{U}-{ }^{14} \mathrm{C}\right] 4-$ methyl-2oxopentanoate amination and conversion into ${ }^{14} \mathrm{CO}_{2}$ was not significantly affected under any of these conditions. Changes in the net uptake of ${ }^{45} \mathrm{Ca}$ and insulin release induced by 4-methyl-2-oxopentanoate were inhibited by the addition of either $\mathrm{NH}_{4}{ }^{+}$or menadione to the incubation medium, both compounds causing a similar degree of inhibition in both parameters. Incubation of islets in the presence of a decreased $p \mathrm{O}_{2}$, on the other hand, failed to affect net ${ }^{45} \mathrm{Ca}$ uptake or insulin release induced by 4methyl-2-oxopentanoate. $\mathrm{Net}^{45} \mathrm{Ca}$ uptake and insulin release by islets incubated in the absence of substrate was not affected by any of these treatments. 

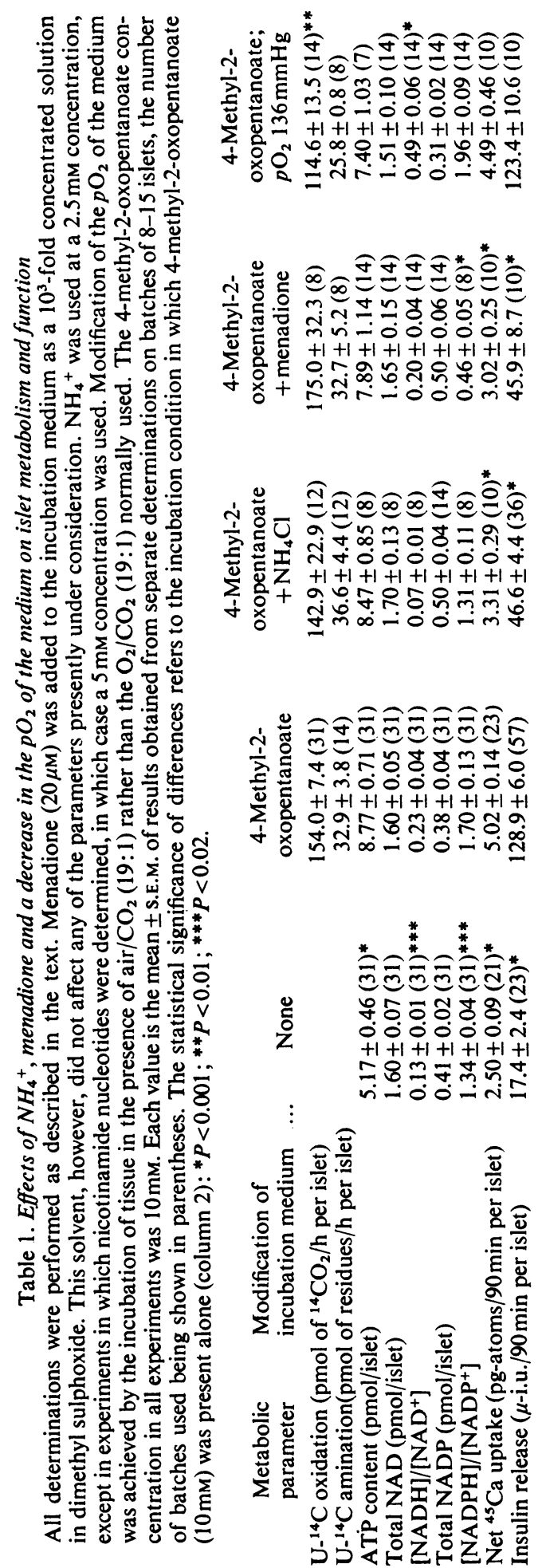

\section{Discussion}

The concentration-dependence of the biochemical, biophysical and secretory responses of islet tissue to 4-methyl-2-oxopentanoate were not identical. All biochemical parameters changed as a hyperbolic function of the extracellular concentration of 4methyl-2-oxopentanoate. The responses observed in insulin release and net ${ }^{45} \mathrm{Ca}$ uptake, however, exhibited a threshold effect, which occurred at $4 \mathrm{~mm}$-4-methyl-2-oxopentanoate. A similar relationship was also observed between islet bioelectrical activity and 4-methyl-2-oxopentanoate concentration (Hutton et al., 1979a). The various parameters could be ranked with respect to the concentration of 4-methyl-2-oxopentanoate that was required to evoke a half-maximal response, i.e. insulin release $>$ net ${ }^{45} \mathrm{Ca}$ uptake $\geqslant[\mathrm{NADPH}] /\left[\mathrm{NADP}^{+}\right]>$respiration $>[\mathrm{NADH}] /\left[\mathrm{NAD}^{+}\right]>[\mathrm{ATP}]$. The existence of such a series could reflect a sequence of causal events. It is noteworthy that the investigation of the effect of various inhibitors on islet-cell metabolism and function in the presence of 4-methyl-2-oxopentanoate have suggested that the insulin-secretory response is dependent on changes in ${ }^{45} \mathrm{Ca}$ transport, which in turn are dependent on oxidative metabolism in islet tissue. Changes in 4-methyl-2-oxopentanoate oxidation, the [NADPH]/[NADP $\left.{ }^{+}\right]$ratio, the $[\mathrm{NADH}] /\left[\mathrm{NAD}^{+}\right]$ratio and net ${ }^{45} \mathrm{Ca}$ uptake, however, do not occur as the consequence of changes in the insulin-secretory rate (Hutton et al., 1979b). The role of ${ }^{45} \mathrm{Ca}$ as a mediator between metabolic and secretory events in islet tissue was further illustrated in the present investigation by the similarity in the concentration-dependence of ${ }^{45} \mathrm{Ca}$ uptake and insulin release and from experiments performed in the presence of $\mathrm{NH}_{4}{ }^{+}$and menadione.

\section{Relationship of metabolic flux to insulin release}

The response of insulin release and net ${ }^{45} \mathrm{Ca}$ uptake to variation in 4-methyl-2-oxopentanoate concentration were correlated with several parameters of islet-cell metabolism, in particular the rates of utilization, decarboxylation, amination and oxidation of 4-methyl-2-oxopentanoate and the rate of islet respiration. For each of these metabolic parameters, the concentration of the oxo acid required to either provoke an increase above the basal value or to evoke a half-maximal response was lower than the corresponding concentration for insulin release. In each case, the argument that the pathway in question provides the signal that initiates the release process can be maintained. As far as the amination of 4-methyl-2-oxopentanoate is concerned, the finding that the intracellular leucine content did not vary over the range of 4-methyl-2-oxopentanoate concentration that evoked different rates of insulin 
secretion (Hutton et al., 1979c) seems to rule out this metabolite as the possible signal.

\section{Possible role of nicotinamide nucleotides in the secretory response}

The participation of nicotinamide nucleotides in the stimulus-secretion coupling mechanism of glucose-induced insulin release has been inferred from studies of the concentration of nucleotides in islet tissue (Panten et al., 1973; Deery \& Taylor, 1973; Trus et al., 1978; Malaisse et al., 1978a) and from the effects on insulin secretion of agents that alter either the total NAD(P)H pool (Deery \& Taylor, 1973; Gunnarsson et al., 1974) or its redox state (Malaisse et al., 1978a; Sener et al., 1978; Ammon et al., 1977). The involvement of NAD or NADP in the stimulus-secretion coupling of 2-oxo acid-induced release is suggested by the finding that 4-methyl-2oxopentanoate, like glucose, increases the fluorescence of nicotinamide nucleotides in intact perifused islets (Panten et al., 1974; Panten, 1975). On the basis of finding a dissociation between the time course of changes in islet fluorescence and insulin release in this system, however, Panten and coworkers have concluded that $\mathrm{NAD}(\mathbf{P}) \mathrm{H}$ does not mediate the insulinotropic action of 2-oxo acids. The present results, which were obtained by enzymic determination of the nicotinamide nucleotide contents of homogenized tissue, contrasted with the findings by Panten et al. (1974) in that the observed increase in the reduced forms of NAD and NADP induced by 4-methyl-2-oxopentanoate occurred as a sustained phenomenon. Similarly the findings by Panten et al. (1974) that the magnitude of the long-term fluorescence response differed markedly between glucose and 4-methyl-2-oxopentanoate was not substantiated in experiments that compared the effects of these two secretagogues on NAD $(P) H$ in the same batches of islets (J. C. Hutton \& W. J. Malaisse, unpublished work). Differences between glucose (Malaisse et al., 1979) and 4-methyl-2oxopentanoate were observed in the present experiments only in so far as the responses of the [NADPH]/ $\left[\mathrm{NADP}^{+}\right]$and $[\mathrm{NADH}] /\left[\mathrm{NAD}^{+}\right]$ratios to variation in the 4-methyl-2-oxopentanoate concentration did not exhibit threshold phenomena and that changes in these ratios in the presence of 4-methyl-2-oxopentanoate were not correlated with one another. The finding that the $[\mathrm{NADH}] /\left[\mathrm{NAD}^{+}\right]$ratio did not change progressively throughout the range of 4-methyl-2-oxopentanoate concentrations that evoked changes in insulin secretion (Figs. 2 and 5) suggested that the NAD redox system is not a mediating factor in the insulin-secretory mechanism of this oxo acid. Experiments performed in the presence of agents that modified the redox state of NAD and NADP in islets (Table 1) also seeti.ed to discount NAD as being of importance in the stimulussecretion coupling mechanism. The hydrogen acceptor, menadione, markedly inhibited insulin release induced by 4-methyl-2-oxopentanoate in the absence of a significant effect on the islet [NADH]/[NAD $\left.{ }^{+}\right]$ ratio. Conversely, a decrease in the $\mathrm{pO}_{2}$ of the medium, which resulted in a marked increase in the $[\mathrm{NADH}] /\left[\mathrm{NAD}^{+}\right]$ratio, did not affect insulin secretion. An important role for NADP in the stimulus-secretion coupling mechanism of 4-methyl2-oxopentanoate-induced insulin release was suggested in concentration-dependence experiments. Moreover, experimental conditions that resulted in a more oxidized state of islet NADP markedly inhibited net ${ }^{45} \mathrm{Ca}$ uptake and insulin release, in the absence of significant effects on islet ATP content or the oxidation and amination of $\left[\mathrm{U}-{ }^{14} \mathrm{C}\right] 4-$ methyl-2-oxopentanoate by islet tissue. It was also evident that the change in [NADPH]/[NADP ${ }^{+}$] induced by 4methyl-2-oxopentanoate occurred with sufficient rapidity for it to serve as a mediator in the stimulussecretion coupling mechanism. The mechanism by which the [NADPH]/[NADP ${ }^{+}$] ratio was increased by 4-methyl-2-oxopentanoate is unclear. It may be argued that changes in the [NADPH]/[NADP $\left.{ }^{+}\right]$ ratio are produced by changes in the rate of 4-methyl2-oxopentanoate degradation. Against this it must be considered that non-metabolizable insulin secretagogues, such as 2-aminonorbornane-2-carboxylic acid, are reported to increase islet nicotinamide nucleotide fluorescence (Joost et al., 1975) and that under anoxic conditions in which 4-methyl-2oxopentanoate catabolism and insulin release are blocked, the islet [NADPH]/[NADP ${ }^{+}$] ratio is still elevated (Hutton et al., 1979b). Conversely the relationship between the [NADPH]/[NADP $\left.{ }^{+}\right]$ratio and oxidation flux could be explained if a more reduced state of these nucleotides regulates 4-methyl2-oxopentanoate catabolism at the site of the initial dehydrogenase reaction, an interesting hypothesis in view of the reported regulatory effects of $\mathrm{NAD}^{+}$ and NADH on other 2-oxo acid dehydrogenases and their associated phosphorylating and dephosphorylating enzymes (Smith et al., 1974; Cooper et al., 1975; Pettit et al., 1975). The results obtained with $\mathrm{NH}_{4}{ }^{+}$or menadione fail to support such an hypothesis. The finding that islet ATP content, the [ATP]/[ADP] ratio and adenylate charge did not change significantly at extracellular concentrations of 4-methyl-2-oxopentanoate above $2 \mathrm{~mm}$ makes it seem more likely that the adenine nucleotide pool plays an important role in the regulation of islet-cell respiration and in the catabolism of this secretagogue. In conclusion, the experimental data are compatible with the view that the metabolism of 4-methyl-2oxopentanoate in islet cells and the associated changes in concentration and/or turnover of reducing equivalents and high-energy phosphate intermediates 
participate in the chain of events leading to stimulation of insulin release by this nutrient.

This work was supported in part by grants from the Belgian Foundation for Scientific and Medical Research (3.4527-75, 3.4537-76 and 3-4528-79). J. C. H. received a Pfizer Travel Award from the European Association for the Study of Diabetes. A. Tinant, S. Procureur and M. Urbain are thanked for their technical assistance, and B. Cocks and C. Demesmaeker for secretarial help.

\section{References}

Alberty, R. A. (1969) J. Biol. Chem. 244, 3290-3302

Ammon, H. P. T., Akhtar, M. S., Niklas, H. \& Hegner, D. (1977) Mol. Pharmacol. 13, 598-605

Atkinson, D. E. (1966) Annu. Rev. Biochem. 35, 85-124

Atkinson, D. E. (1977) Cellular Energy Metabolism and its Regulation, Academic Press, New York

Cooper, R. H. P., Randle, P. J. \& Denton, R. M. (1975) Nature (London) 237, 808

Deery, D. J. \& Taylor, K. W. (1973) Biochem. J. 134, 557-563

Gunnarsson, R., Berne, C. \& Hellerström, C. (1974) Biochem. J. 140, 487-494

Hutton, J. C., Atwater, I. \& Malaisse, W. J. (1979a) Horm. Metab. Res., in the press

Hutton, J. C., Sener, A., Herchuelz, A., Atwater, I., Kawazu, S., Boschero, A. C., Somers, G., Devis, G. \& Malaisse, W. J. (1979b) Endocrinology in the press

Hutton, J. C., Sener, A. \& Malaisse, W. J. (1979c) Biochem. J. 184, 291-301

Joost, H. G., Panten, U., Ishida, H., Poser, W. \& Hasselblatt, A. (1975) Life Sci. 16, 247-254
Lacy, P. E. \& Kostianovsky, M. (1967) Diabetes 6, 35-39

Lowry, O. H. \& Passonneau, J. V. (1972) A Flexible System of Enzymatic Analysis, Academic Press, New York and London

Malaisse, W. J., Brisson, G. R. \& Malaisse-Lagae, F. (1970) J. Lab. Clin. Med. 76, 895-902

Malaisse, W. J., Hutton, J. C., Kawazu, S. \& Sener, A. (1978a) Eur. J. Biochem. 87, 121-130

Malaisse, W. J., Hutton, J. C., Sener, A., Levy, J., Herchuelz, A., Devis, G. \& Somers, G. (1978b) J. Membr. Biol. 38, 193-208

Malaisse, W. J., Hutton, J. C., Kawazu, S., Herchuelz, A., Valverde, I. \& Sener, A. (1979) Diabetologia 16, 331-341

Malaisse-Lagae, F. \& Malaisse, W. J. (1971) Endocrinology 88, 72-80

Panten, U. (1975) Naunyn-Schmiedeberg's Arch. Pharmacol. 291, 405-420

Panten, U., Christians, J., Kriegstein, E., Poser, W. \& Hasselblatt, A. (1973) Diabetologia 9, 477-482

Panten, U., Christians, J., Kriegstein, E., Poser, W. \& Hasselblatt, A. (1974) Diabetologia 10, 149-154

Pettit, F. H., Pelley, J. W. \& Reed, L. J. (1975) Biochem. Biophys. Res. Commun. 65, 575-582

Sener, A., Hutton, J. C., Kawazu, S., Boschero, A. C., Somers, G., Devis, G., Herchuelz, A. \& Malaisse, W. J. (1978) J. Clin. Invest. 62, 868-878

Smith, C. M., Bryła, J. \& Williamson, J. R. (1974) J. Biol. Chem. 249, 1497-1505

Stanley, P. E. \& Williams, S. G. (1969) Anal. Biochem. 29, 381-392

Trus, M. D., Hintz, C. S., Weinstein, J. B., Williams, A. D., Pagliara, A. S. \& Matchinsky, F. M. (1978) Life Sci. 22, 809-816 